Int. J. Electrochem. Sci., 11 (2016) $6873-6885$

\title{
Corrosion of Stainless Steel in Simulated Tide of Fresh Natural Seawater of South East Pacific
}

\author{
Diego A. Fischer ${ }^{1,2}$, Leslie Daille ${ }^{2,3}$, Javiera Aguirre ${ }^{2,4}$, Carlos Galarce ${ }^{1,2}$, Francisco Armijo ${ }^{2,5}$, \\ Rodrigo De la Iglesia, ${ }^{2,3}$, Gonzalo Pizarro ${ }^{1,2}$, Ignacio Vargas ${ }^{1,2}$, Magdalena Walczak $^{2,4, *}$ \\ ${ }^{1}$ Departamento de Ingeniería Hidráulica y Ambiental, Escuela de Ingeniería, Pontificia Universidad \\ Católica de Chile, Vicuña Mackenna 4860, Macul, Santiago, Chile. \\ ${ }^{2}$ Marine Energy Research \& Innovation Center (MERIC), Avda. Apoquindo 2827, Santiago, Chile. \\ ${ }^{3}$ Departamento de Genética Molecular y Microbiología, Facultad de Ciencias Biológicas, Pontificia \\ Universidad Católica de Chile, Avda. Libertador Bernardo O'Higgins 340, Santiago, Chile \\ ${ }^{4}$ Departamento de Ingeniería Mecánica y Metalúrgica, Escuela de Ingeniería, Pontificia Universidad \\ Católica de Chile, Vicuña Mackenna 4860, Macul, Santiago, Chile. \\ ${ }^{5}$ Laboratorio de Bioelectroquímica, Departamento de Química Inorgánica, Facultad de Química, \\ Pontificia Universidad Católica de Chile Vicuña Mackenna 4860, 7820436, Macul, Santiago, Chile. \\ *E-mail: mwalczak@ing.puc.cl
}

doi: $10.20964 / 2016.08 .50$

Received: 4 May 2016 / Accepted: 7 June 2016 / Published: 7 July 2016

\begin{abstract}
Whereas the initiation and advance of localized corrosion often limits a prolonged application of stainless steel in seawater, the particular conditions that trigger this type of corrosion are not fully understood due to high variability of water parameters and diversity of the biological component. In this study, coupons of AISI 304 and 316L were tested in fresh natural seawater of South East Pacific (coast of central Chile) employing two flow-through exposition racks: one keeping the coupons at full immersion and one allowing the simulation of tides through variable level of water effecting dry-wet cycles. Loss of weight and electrochemical characterization after 1, 5, 15 and 30 weeks of exposition revealed that for both materials the intermittent immersion results in considerably less corrosion, both general and localized. After 15 weeks, all samples showed a negative shift of OCP, i.e. the opposite of ennoblement, which is explained by the activity of microorganisms associated with change of season.
\end{abstract}

Keywords: marine corrosion, stainless steel, natural seawater, simulated tide, Pacific Ocean

\section{FULLTEXT}

(C) 2016 The Authors. Published by ESG (www.electrochemsci.org). This article is an open access article distributed under the terms and conditions of the Creative Commons Attribution license (http://creativecommons.org/licenses/by/4.0/). 